Subscriber access provided by ZHAW Hochschulbibliothek

\title{
Energy and the Environment
}

\section{Non-Volatile Particulate Matter Emissions of a Business Jet Measured at Ground Level and Estimated for Cruising Altitudes}

Lukas Durdina, Benjamin Tobias Brem, David Schönenberger, Frithjof Siegerist, Julien Gérard Anet, and Theo Rindlisbacher

Environ. Sci. Technol., Just Accepted Manuscript • DOI: 10.1021/acs.est.9b02513 • Publication Date (Web): 03 Oct 2019

Downloaded from pubs.acs.org on October 4, 2019

\section{Just Accepted}

"Just Accepted" manuscripts have been peer-reviewed and accepted for publication. They are posted online prior to technical editing, formatting for publication and author proofing. The American Chemical Society provides "Just Accepted" as a service to the research community to expedite the dissemination of scientific material as soon as possible after acceptance. "Just Accepted" manuscripts appear in full in PDF format accompanied by an HTML abstract. "Just Accepted" manuscripts have been fully peer reviewed, but should not be considered the official version of record. They are citable by the Digital Object Identifier (DOI®). "Just Accepted" is an optional service offered to authors. Therefore, the "Just Accepted" Web site may not include all articles that will be published in the journal. After a manuscript is technically edited and formatted, it will be removed from the "Just Accepted" Web site and published as an ASAP article. Note that technical editing may introduce minor changes to the manuscript text and/or graphics which could affect content, and all legal disclaimers and ethical guidelines that apply to the journal pertain. ACS cannot be held responsible for errors or consequences arising from the use of information contained in these "Just Accepted" manuscripts. 


\section{Non-Volatile Particulate Matter Emissions of a Business Jet Measured at Ground Level and Estimated for Cruising Altitudes}

${ }^{a}$ Laboratory for Advanced Analytical Technologies, Empa, Dübendorf, CH-8600, Switzerland

${ }^{\mathrm{b}}$ Laboratory for Air Pollution and Environmental Technology, Empa, Dübendorf, CH-8600, Switzerland ${ }^{\mathrm{c}}$ SR

Technics Switzerland AG, Zurich-Airport, CH-8058, Switzerland

${ }^{\mathrm{d}}$ Centre for Aviation, School of Engineering, Zurich University of Applied Sciences, Winterthur, CH-8401,

Switzerland

${ }^{\mathrm{e}}$ Federal Office of Civil Aviation FOCA, Bern, CH-3003, Switzerland

${ }^{1}$ now at: Centre for Aviation, School of Engineering, Zurich University of Applied Sciences, Winterthur, CH-8401, Switzerland

${ }^{2}$ now at: Laboratory for Atmospheric Chemistry, Paul Scherrer Institute, Villigen, CH-5232 Switzerland

*Corresponding author; email address: lukas.durdina@zhaw.ch

\section{Abstract}

Business aviation is a relatively small but steadily growing and little investigated $\mathrm{kN}$ thrust are certified only for visible smoke and are excluded from the non-volatile particulate matter (nvPM) standard. Here, we report nvPM emission characteristics of a widely used small turbofan engine determined in a ground test of a Dassault Falcon 900EX business jet. These are the first reported nvPM emissions of a small in-production turbofan engine determined with a standardized measurement system used for emissions certification of large turbofan engines. The ground level measurements together with a detailed engine performance model were used to predict emissions at cruising altitudes. The measured nvPM emission characteristics strongly depended on engine thrust. The geometric mean diameter increased from $17 \mathrm{~nm}$ at idle to $45 \mathrm{~nm}$ at take-off. The nvPM emission indices peaked at low thrust levels ( $7 \%$ and $40 \%$ take-off thrust in terms of 
nvPM number and mass, respectively). A comparison with a commercial airliner shows that a business jet may produce higher nvPM emissions from flight missions as well as from landing and take-off operations. This study will aid the development of emission inventories for small aircraft turbine engines and future emission standards.

\section{TOC art / graphical abstract}

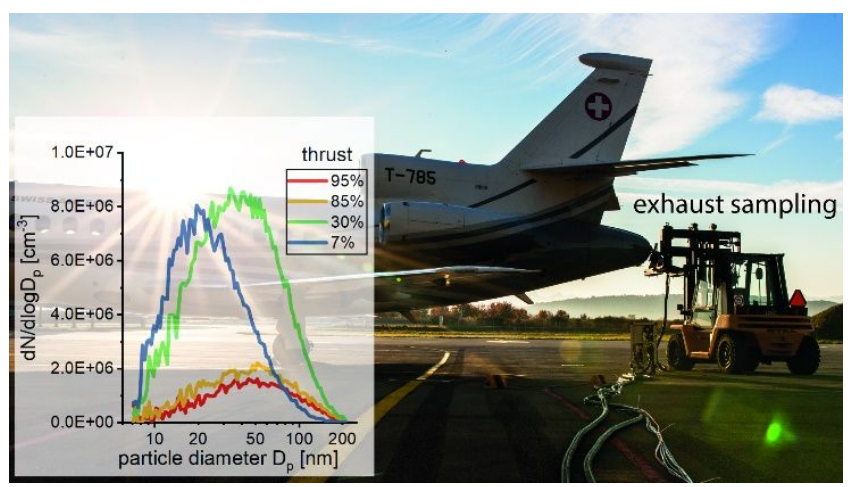

\section{INTRODUCTION}

As the demand for air travel surges, fuel burn from commercial aviation is expected to double in the next 15 years. ${ }^{1}$ Thus, aircraft engine emissions will also increasingly affect climate and air quality. Commercial aviation accounts for approximately $2 \%$ of global man-made $\mathrm{CO}_{2}$ emissions. ${ }^{2-4}$ Besides $\mathrm{CO}_{2}$ and water vapor, aircraft engines also emit gaseous pollutants $\left(\mathrm{NO}_{\mathrm{x}}\right.$, $\mathrm{SO}_{\mathrm{x}}, \mathrm{CO}$, unburned hydrocarbons (HC)) and soot. Soot is composed mostly of light absorbing carbon (black carbon, $\mathrm{BC}$ ). In the aircraft jet engine emission standard, BC is reported as nonvolatile particulate matter (nvPM; particles that are solid at the engine exit plane that do not volatilize when heated to $\left.350{ }^{\circ} \mathrm{C}\right) .{ }^{5,6}$ Aviation nvPM emissions absorb solar radiation, affect cloud formation, and deteriorate air quality at airports and in nearby communities..$^{3,4,7-11}$ Due to their potential health and climate impacts, various research programs have focused on characterization of particle emissions from aircraft engines, development of measurement 
52 techniques and predictive models for estimating aviation nvPM emissions. ${ }^{12-17}$ Recent research

has been motivated also by the development of a certification standard for nvPM emissions of new commercial aircraft turbine engines. ${ }^{18-22}$ The International Civil Aviation Organization (ICAO) has adopted the nvPM standard that applies to all engine types rated $>26.7 \mathrm{kN}$ thrust in production on or after 1 January $2020 .{ }^{5}$ In the longer term, regulatory limits for nvPM number as well as nvPM mass emissions are expected to be enforced. ${ }^{6}$ However, since small engines are excluded from the nvPM standard, nvPM emissions of business jets remain largely unknown.

Similar to commercial aviation, business aviation has flourished. The fleet is predicted to grow worldwide by $33 \%$ in the next 8 years. ${ }^{23}$ Although business aviation consumes only around $2 \%$ of the world's jet fuel ${ }^{24,25}$, small engines used on business aircraft may produce high nvPM emissions relative to their fuel burn due to technical and economic reasons and lack of emission regulations. Small engines rated $\leq 26.7 \mathrm{kN}$ thrust are regulated for visible smoke only via the smoke number (SN). Moreover, the certification SN data for these engines are not part of the publicly available ICAO emissions databank. ${ }^{26}$ Thus, although methods for estimating nvPM emissions from SN have been developed ${ }^{27,28}$, their applicability to small turbine engines (turboprop and turboshaft as well as turbofan) is limited and ambiguous. To date, no nvPM emission indices (EI; amount of pollutant per $\mathrm{kg}$ fuel burned) have been reported for unregulated small turbine engines using the methodology used for emissions certification of large turbofan engines. Previously, nvPM EIs of a widely used turboprop have been reported from exhaust samples taken $10-15 \mathrm{~m}$ behind the aircraft's tail using a simplified sampling system. ${ }^{29}$ The regulatory nvPM measurement system has been demonstrated on a small turbofan engine in a study of fuel composition effects on nvPM emissions, but no EIs have been reported. ${ }^{19}$ 
Here, we report nvPM emission characteristics of a widely used small turbofan engine measured at ground level and modeled for cruising altitudes. We measured gaseous and nvPM emissions from a Honeywell TFE731-60 turbofan engine on a Dassault Falcon 900EX aircraft. We deployed the Swiss Mobile Aircraft Engine Emissions Measurement System (SMARTEMIS), which serves as a global reference system for the regulatory nvPM measurements. We report the EIs of nvPM number and mass as well as particle size distributions at ground level as a function of thrust from ground idle to take-off. We calculated nvPM emissions from the standardized landing and take-off cycle (LTO), which consists of four static thrust levels that approximate airport operations under $3000 \mathrm{ft}$ (900 m) above ground: taxi (7\% thrust), approach (30\% thrust), climb-out (85\% thrust), and take-off (100\% thrust). We also developed a detailed engine performance model to estimate nvPM emissions at cruising altitudes and compared the emission estimates with previous studies of commercial airliners.

\section{MATERIALS AND METHODS}

Engine emission tests. The emission measurements were performed in a static ground-level test of the central engine of a Dassault Falcon 900EX (Figure 1). The engine was fueled with military-grade JP-8 fuel, which has nearly the same specifications as the commercial Jet A-1 but contains the following additives: a lubricity enhancer $(0.1 \%$ mass $)$, an icing inhibitor $(0.1 \%$ volume), and a static dissipater (ppm level). ${ }^{30}$ The fuel batch used fulfilled the requirements for the fuel used in aircraft turbine engine emission testing according to Appendix 4 of the ICAO Annex $16 \mathrm{Vol} \mathrm{II}^{5}$ (S1 in the online supporting information, SI). The weather during the test was dry and sunny with a temperature range from $11.2^{\circ} \mathrm{C}$ to $20.2{ }^{\circ} \mathrm{C}$, relative humidity between $40 \%$ and $70 \%$ and ambient pressure in the range from $96.5 \mathrm{kPa}$ to $96.8 \mathrm{kPa}$. The engine test consisted 
of a warm-up sequence and 11 test points on a descending power curve from take-off to idle (S2 in the SI). The engine was kept at each condition typically for 3 minutes (depending on the emissions stabilization time). The engine test was run three times on the same day. We used the low-pressure rotor speed ( $\mathrm{N} 1$; rotational speed of the low pressure compressor and turbine) for setting the engine test points, using a correlation of thrust with $\mathrm{N} 1$ for the international standard atmosphere (ISA) conditions at sea level $\left(15^{\circ} \mathrm{C}\right.$ and $\left.101.325 \mathrm{kPa}\right)$ provided by the engine manufacturer. The N1 settings could be repeated within $0.5 \%$ for all points except for maximum thrust, which was set by pushing the thrust lever to take-off position. The required take-off thrust set by the engine controller is typically below the maximum rated value and it varies with aircraft weight and ambient conditions. The average N1 from the three test runs at take-off was $98 \%$ (range $97.3 \%-98.7 \%$ ), corresponding to $\sim 95 \%$ of the rated sea level thrust. Common for small turbofan engines, the engine had an exhaust mixer, which mixed the hot core exhaust gases and the cold bypass air in a common nozzle. The mixed exhaust samples were extracted $\sim 30 \mathrm{~cm}$ downstream of the engine exhaust nozzle exit plane (a plane perpendicular to the engine center line at the exhaust nozzle exit) with a sampling probe made of Inconel 600 alloy. The probe had a cruciform design with 12 orifices that provided a representative exhaust gas sample according to the smoke emissions certification standard. ${ }^{5}$ 


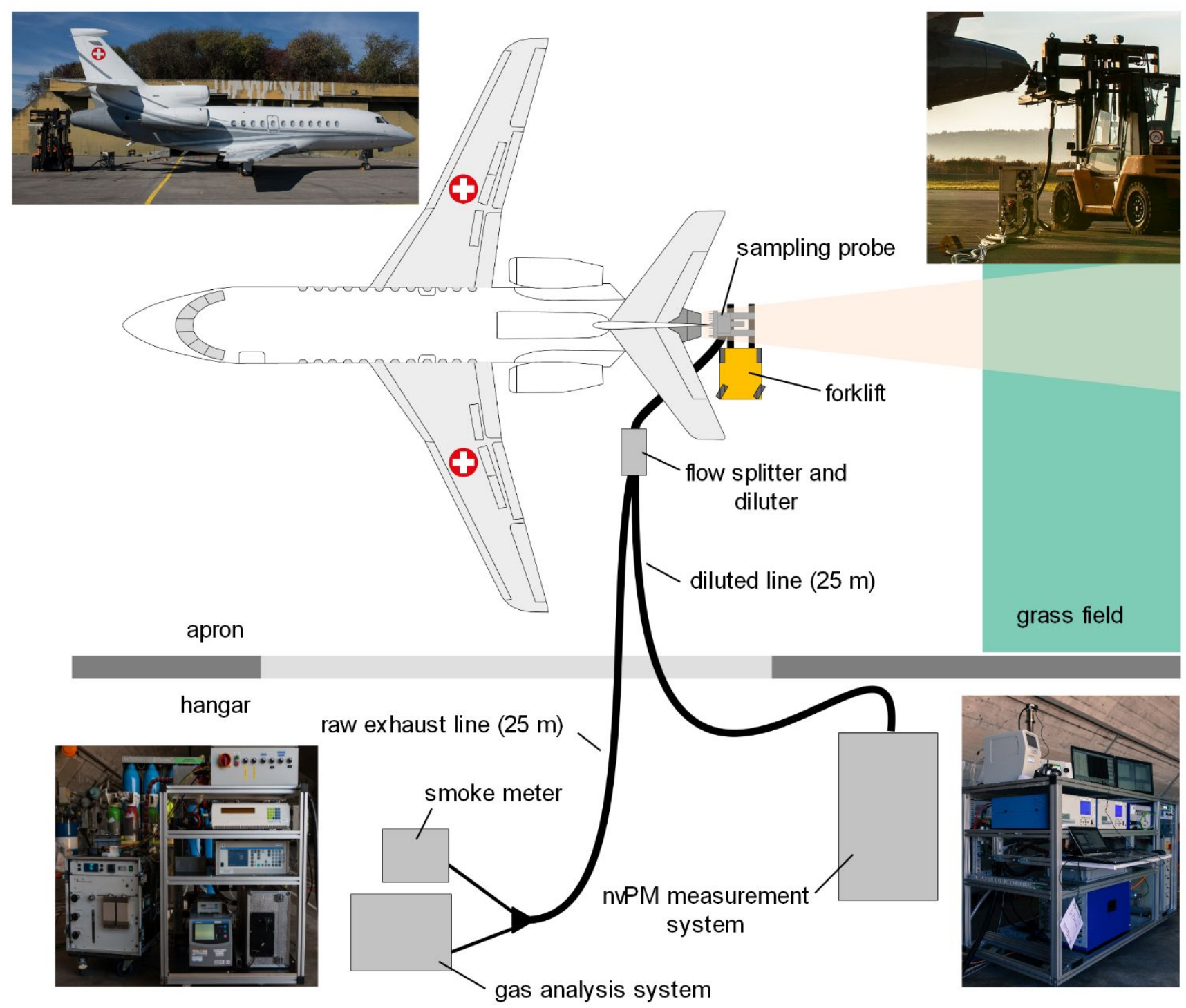

113 Figure 1 Schematic of the experimental setup for the emission tests on the center engine of

114 the Dassault Falcon 900EX done with SMARTEMIS.

116 certification standard and was described in detail previously ${ }^{18,20,22,31}$. Briefly, the probe was

117 connected to a $5.5 \mathrm{~m}$-long stainless steel tubing heated to $160^{\circ} \mathrm{C}$ and with an inner diameter (ID)

118 of $8 \mathrm{~mm}$. At the inlet of the diluter assembly, the sample was split into the pressure control line,

119 the nvPM transfer section, and the raw gas line. The raw gas line $\left(160^{\circ} \mathrm{C}\right.$, length $25 \mathrm{~m}, 6 \mathrm{~mm}$ ID, 
flow of 18 slpm, carbon-filled polytetrafluoroethylene (PTFE)) transported the raw exhaust sample to the gas and smoke analysis system $\left(\mathrm{CO}_{2}, \mathrm{CO}, \mathrm{NO}_{\mathrm{x}}, \mathrm{SO}_{2}, \mathrm{HC}\right.$ and $\left.\mathrm{SN}\right)$. In the diluter assembly, a Dekati DI-1000 ejector diluter diluted the raw gas sample with dry synthetic air by a factor of $\sim 8$. The diluted sample was drawn through a trace-heated line $\left(60^{\circ} \mathrm{C}\right.$, length $25 \mathrm{~m}, 8$ mm ID, flow of $25 \mathrm{slpm}$, carbon-filled PTFE) to the particle instrumentation. The latter determined the nvPM number concentration of particles $>10 \mathrm{~nm}$ (AVL Particle Counter Advanced, AVL APC), the nvPM mass concentration (AVL Micro Soot Sensor, AVL MSS Model 483), and the particle size distribution (Scanning Mobility Particle Sizer, TSI SMPS Model 3938). All the particle instruments were factory-calibrated prior to the measurement campaign. The size distribution measurement is not required by the ICAO nvPM standard; however, it provides information relevant for health and climate effects studies. In the context of the nvPM mass and number measurement, size distribution measurements help to explain the relationship between nvPM mass and number concentrations and are important for an accurate sampling system loss correction.

Particle loss correction. All data presented here are corrected for particle loss to the inner walls of the sampling system, which is a significant artifact in gas turbine exhaust sampling. The main particle loss mechanisms are diffusion due to the long sampling lines ( $\sim 34 \mathrm{~m}$ from probe inlet to the instrument inlet), and thermophoresis due to a temperature gradient between the exhaust gas and the sampling line wall. The thermophoretic loss for the engine tested was negligible due to its mixed-flow exhaust nozzle that diluted the hot core exhaust flow with the cold bypass air upstream of the sampling probe (the modeled highest mixed gas temperature was $\sim 200^{\circ} \mathrm{C}$, the line temperature was held at $160^{\circ} \mathrm{C}$ ). The size-dependent diffusional losses were calculated using the measured particle size distributions (PSD) and a modeled penetration function for the 
143 sampling system. The size-dependent system penetration functions were calculated according to 144 a standardized method developed for the aircraft engine nvPM testing published in the SAE 145 Aerospace Recommended Practice (ARP) 6481..$^{32}$ The PSD measured was divided by the system 146 penetration function for the SMPS (exhaust probe inlet to SMPS inlet) to obtain the PSD at the 147 engine exit plane. The exit plane PSD, both number and mass-based, were then fitted with 148 lognormal distributions. The mass distributions were obtained by assuming an average particle 149 density of $1 \mathrm{~g} / \mathrm{cm}^{3}$ independent of thrust and particle size. Effective density of aircraft engine 150 soot is particle size and thrust dependent, however, measurements have shown that the average 151 density (mass / volume of the PSD) is nearly constant as a function of thrust and geometric mean 152 diameter (GMD). ${ }^{22}$ Finally, the distributions at the engine exit plane were multiplied by the 153 penetration functions from the sampling probe inlet to the inlets of the corresponding nvPM 154 instruments. The nvPM number concentration was also corrected for the losses in the instrument 155 (losses in the volatile particle remover and the counting efficiency cut-off). The resulting 156 correction factors are the ratios of the integrated PSD at the engine exit plane to the PSD at the 157 instrument inlets for mobility diameters $\geq 10 \mathrm{~nm}$. The number-based correction factors were in 158 the range 2-6 (i.e., 2- to 6-fold losses) and the mass-based correction factors were in the range $1.2-1.4$ (i.e., $20 \%-40 \%$ losses) (S3 in the online SI).

Emission indices. The nvPM EIs were calculated using one-minute averages of the nvPM mass

161 and number, $\mathrm{CO}, \mathrm{CO}_{2}, \mathrm{HC}$, and $\mathrm{NO}_{\mathrm{x}}$ concentrations and the complete nvPM EI equations, which 162 include a correction for ambient background residual nvPM. ${ }^{33}$ This correction may be required

163 because in the mixed-flow engine configuration the ambient air dilutes the core flow upstream of 164 the sampling probe. Without considering the ambient background nvPM, the nvPM EIs may be 165 overestimated. For the worst-case scenario encountered in the ambient air checks pre- and post- 
166

167

168

169

170

171

172

173

174

175

176

177

178

179

180

181

182

183

184

185

186

187

188

test (ambient nvPM mass $3.5 \mu \mathrm{g} / \mathrm{m}^{3}$ and 8000 particles $/ \mathrm{cm}^{3}$ ), the effect of the ambient background nvPM on the nvPM EIs was $<5 \%$ for nvPM mass and $<1 \%$ for nvPM number and it was the highest at idle. The relative uncertainty (95\% confidence) of the loss-corrected EIs was estimated to be $20 \%$ (propagation of the systematic and random errors in the EIs and particle loss correction). The loss-corrected nvPM EIs were then interpolated as a function of sea-level static thrust using $6^{\text {th }}$ order polynomials. The interpolated EIs and fuel flow were used to calculate the LTO cycle emissions, which are simplified estimates of emissions from airport operations $<915$ $\mathrm{m}(3000 \mathrm{ft})$ above ground level. To calculate the standard LTO emissions, the EI in each mode is multiplied by fuel flow and the mode duration $(26,4,2.2$, and 0.7 minutes for taxi, approach, climb-out, and take-off, respectively). ${ }^{5}$

Emission estimates at cruising altitude. We calculated the nvPM emissions at cruise Mach number of 0.8 at the reference cruising altitude of 35,000 $\mathrm{ft}$ (flight level (FL) 350) in the international standard atmosphere (ISA) at temperatures ISA $\pm 10{ }^{\circ} \mathrm{C}$, and at Mach 0.8 at FL400 (ISA) at maximum cruise thrust according to the engine manufacturer's specifications. To estimate the combustion-relevant engine parameters at these conditions, we developed a detailed calibrated engine performance model using the GasTurb 13 software package. ${ }^{34}$ The model provides the combustor inlet pressure (P3), temperature (T3) as well as the combustor exit airfuel ratio (AFR) needed for correcting the reference mass emission indices $\left(\mathrm{EI}_{\mathrm{m}}\right)$ at ground $\left(\mathrm{EI}_{\mathrm{m}}\right.$ at the same $\mathrm{T} 3$ as at cruise) using known empirical equations. ${ }^{31,35}$ The number emission indices $\left(E I_{n}\right)$ at cruise were calculated from the ratio $\mathrm{EI}_{\mathrm{n}} / \mathrm{EI}_{\mathrm{m}}$ as a function of $\mathrm{T} 3$, which is based on the assumption that the GMD is a function of T3. ${ }^{31,36} \mathrm{We}$ compared the results of this method with a more elaborate one that estimates the cruise nvPM EIs from nvPM mass concentration, PSD properties (GMD and geometric standard deviation, GSD) and engine performance at cruise (see 
S4 in the SI for the detailed description of the engine performance model and the cruise emissions calculation).

\section{RESULTS AND DISCUSSION}

Particle size distribution characteristics. The PSD characteristics depended strongly on engine thrust (Figure 2). The GMD was smallest at idle $(\sim 17 \mathrm{~nm})$, followed by an initial steep increase up to $\sim 40 \%$ thrust. After this point, there was negligible further increase in size with increase in thrust. The largest size was observed at take-off thrust ( $45 \mathrm{~nm})$. The GSD of the measured PSD ranged from 1.85 to 1.95 (mean value for all test points was 1.91) independent of thrust. The PSD followed the lognormal distribution best at idle $\left(\mathrm{R}^{2}=0.99\right)$ and departed from lognormality with increasing thrust $\left(\mathrm{R}^{2}=0.95\right.$ at take-off). The GMD increase with engine thrust is consistent with previous emission measurements directly behind turbofan engines with conventional (single annular) combustors. ${ }^{18,19,29,31,37-39}$ However, Figure $2 \mathrm{~b}$ shows that compared to a common large turbofan engine CFM56-7B, the GMD was larger at all thrust levels. As the GMD increased with thrust, the particle concentration increased as well from idle up to $\sim 30 \%$ thrust, but it decreased with further increase in thrust with the minimum at take-off (Figure 2a). Similar PSD characteristics have not been reported for a commercial turbofan engine before. Previous studies found the largest GMD at engine conditions that produced the highest nvPM mass emission indices for staged combustor engines as well as for single annular combustor engines. For single annular combustor engines (most engines in service), this occurs typically at take-off thrust $^{14,18,29,31,38,39}$. Our results corroborate that the GMD of nvPM produced by jet engines with unstaged combustors increases with engine thrust (or T3) and it does not necessarily correlate with the nvPM mass concentration in the exhaust. ${ }^{31}$ We note that the concentrations of the PSDs 
211 in Figure 2a have not been corrected for the bypass air dilution. The bypass air dilution does not

212 affect the calculated emission indices, which were used in further analysis.
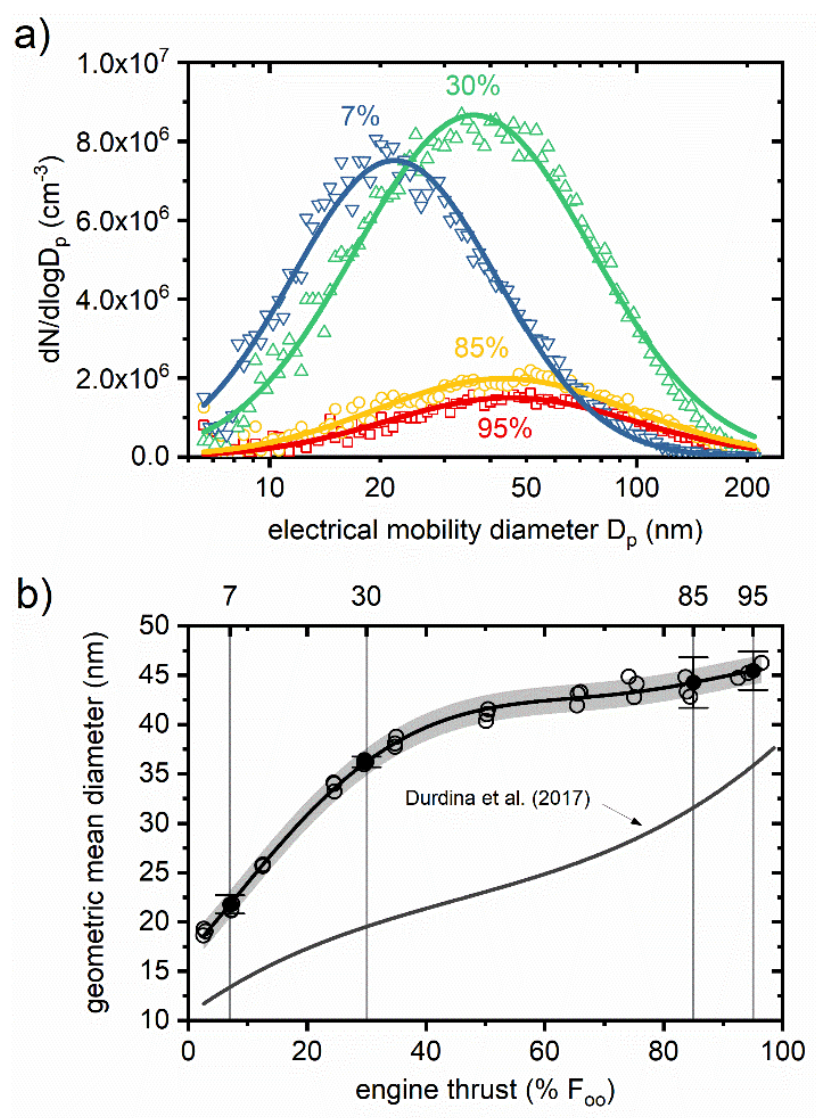

Figure 2 Particle size distributions at the engine exit plane (mixed flow nozzle, no bypass geometric mean diameter as a function of rated thrust, $F_{\mathrm{oo}}(\mathrm{b})$. Shaded area in (b) represents the standard error of the fit $(95 \%$ confidence). The error bars $(95 \%$ confidence) for the LTO points are the combined uncertainties of the random standard uncertainty

219 (standard deviation of the mean, $\mathbf{N}=3$ ) and the total uncertainty in the GMD (5\%). The 220 curve from Durdina et al. (2017) ${ }^{31}$ is for the exit plane of a CFM56-7B engine (Boeing 737800). 
223 Emission indices. The emission indices of nvPM mass and number varied with engine thrust by 224 more than an order of magnitude and peaked at low thrust levels (Figure 3). The EI $\mathrm{I}_{\mathrm{m}}$ peaked at $225 \sim 40 \%$ thrust and was the lowest and similar in magnitude at take-off and idle (Figure $3 \mathrm{a}$ ). In 226 contrast, the $\mathrm{EI}_{\mathrm{n}}$ peaked near idle power ( $\sim 7 \%$ rated thrust) and decreased steadily with 227 increasing thrust with a minimum at take-off (a factor of $\sim 19$ lower than at idle; Figure 3b). Such 228 nvPM EI characteristics have not been reported for a commercial turbofan before. Typically, the $\mathrm{EI}_{\mathrm{m}}$ of turbofan engines of various sizes with conventional combustors increases with thrust with a maximum at or near take-off. ${ }^{20,29,31,38,40} \mathrm{The}_{\mathrm{EI}}$ often follows an S-shaped curve with a maximum at idle, minimum at $\sim 20 \%$ thrust, and further increase with thrust with a plateau at mid-range to maximum thrust (see gray lines in Figure 3 for comparison with a previous study of the CFM56-7B turbofan engine used on the Boeing 737-800 31 ). dependence than the widely used CFM56-7B engine, but they also differed strongly in magnitude for most of the engine conditions. The $\mathrm{EI}_{\mathrm{m}}$ was higher by a factor of $\sim 200$ at $30 \%$

237 thrust (approach mode in the LTO cycle); whereas at take-off, it was up to a factor of 2 lower 238 (Figure 3a). The $\mathrm{EI}_{\mathrm{n}}$ was higher by up to a factor of 30 at taxi and approach thrust, whereas at 239 take-off power it was up to a factor of 3 lower than found in the previous study for the airliner 240 engine (Figure $3 \mathrm{~b}$ ). The relatively high nvPM EIs at low thrust compared to a conventional large 241 turbofan engine indicate that a small aircraft with nvPM emission characteristics as reported here 242 may be a significant nvPM source during low thrust operations (idle, taxiing, approach and 243 landing) despite its lower fuel burn. 
a)

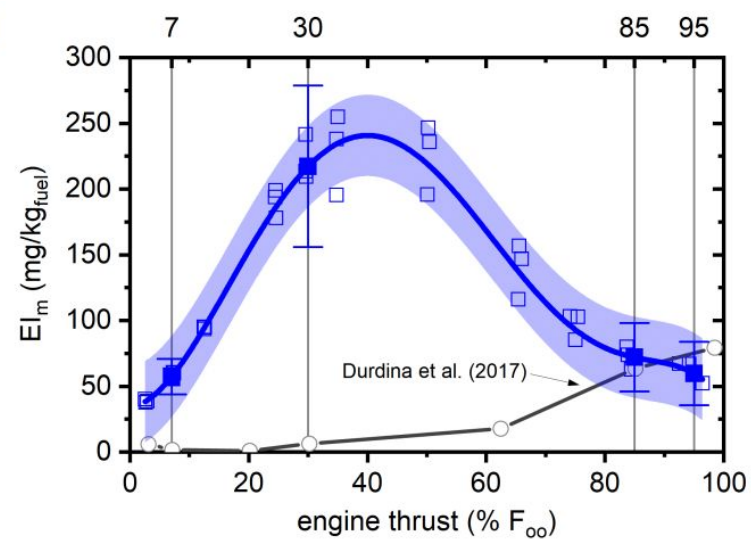

b)

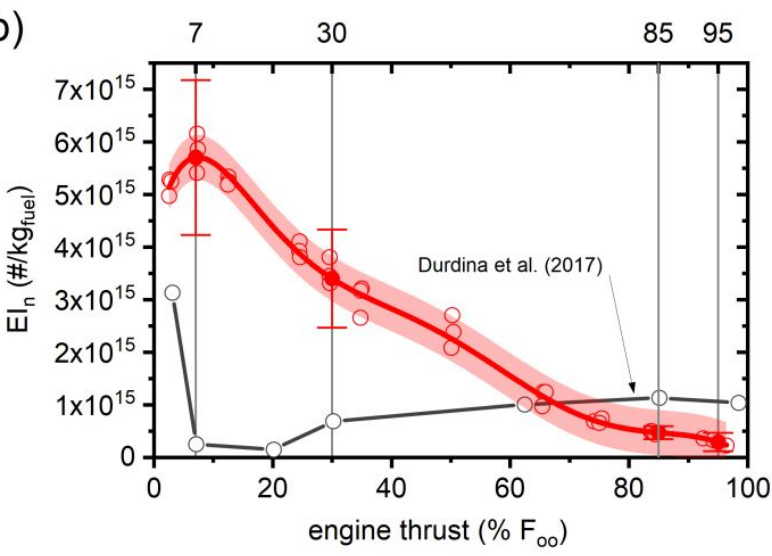

Figure 3 Emission indices (particle loss corrected) of nvPM mass (a) and nvPM number (b) as a function of thrust. The shaded areas are standard errors of the fits (95\% confidence). The error bars (95\% confidence) for the LTO points are the combined uncertainties of the random standard uncertainty (standard deviation of the mean, $N=3$ ) and the total uncertainty in the measured EIs (20\%). The data from Durdina et al. $(2017)^{31}$ are for the CFM56-7B26 engine (Boeing 737-800).

Note that the two studies compared here used different fuels, which affected the nvPM emissions. The fuel hydrogen mass content, which has been used as the correlating parameter for

254 fuel effects on nvPM emissions ${ }^{19,20,41,42}$, was $13.5 \%$ compared to Durdina et al. (2017) ${ }^{31}$ who 255 used fuel with $14.3 \%$. Fuels with higher hydrogen content burn cleaner and the effect on nvPM 
256 decreases with increasing engine thrust. ${ }^{19,20,42}$ According to the predictive model of Brem et al. ${ }^{20}$,

257 the difference between the nvPM EIs for two fuels with hydrogen mass content difference of

$258 \quad 0.5 \%$ (maximum range in their study) is $\sim 50 \%$ at $30 \%$ thrust and $\sim 5 \%$ at take-off thrust.

259 Nevertheless, the fuel used here is within the specifications for certification fuel and its lower 260 hydrogen content is representative of fuel used in North America. ${ }^{43}$

261 Another source of variability in nvPM emissions is ambient conditions. The variation in 262 the measured EIs shown in Figure 3 (coefficient of variation 2-15\%) for a given thrust level is 263 dominated primarily by the ambient temperature variability. As the ambient temperature varied, 264 the combustor conditions for a given N1 varied with changes in air density, which affected the nvPM emissions measurably. Negative correlation of nvPM emissions with ambient temperature

266 has been observed before ${ }^{18}$, but no corrections for ambient effects have been developed yet. As

267 the mean ambient temperature in the three runs was $\sim 15^{\circ} \mathrm{C}$ and the pressure was near standard 268 sea level pressure, the interpolated EIs can be considered representative for sea level standard 269 conditions.

271 LTO cycle emissions. The LTO cycle emissions were dominated by the taxi and approach 272 modes (Figure 4). This is a result of the peak nvPM emissions at low thrust (Figure 3) and the 273 longest times in those LTO modes (Table 1). The taxi and approach modes together constituted $27471 \%$ of the total nvPM mass and $95 \%$ of the total nvPM number. This finding contrasts the LTO 275 cycle emissions of a Boeing 737-800 (and other airliners), which are dominated by the climb and 276 take-off modes. ${ }^{31}$ In comparison, the nvPM emissions from the taxi and approach modes of the 277 Boeing $737-800$ made up only $3 \%$ of the total nvPM mass and $33 \%$ of the total nvPM number. 278 Interestingly, the total LTO emissions were higher than those of the airliner. The nvPM mass 
279 was higher by $22 \%$ and the nvPM number was higher by a factor of 2 . Thus, a business jet may 280 be an important contributor to local air pollution, depending on the actual LTO operations.

281 We note that the certification LTO cycle likely overestimates emissions compared to a 282 performance-based LTO model, but it is valuable for comparing emissions performance of 283 different engines. The certification LTO cycle is meant to be an approximation, thus the thrust 284 levels as well as the times in mode may be overestimated, especially for small airports serving 285 private aviation. However, a low-emitting engine in the certification LTO cycle is expected to 286 have good emissions performance also in the real world. To evaluate emissions performance of 287 different engines from certification data, the total LTO cycle emissions are normalized to rated 288 take-off thrust. ${ }^{5}$ The TFE731-60 engine (rated thrust $22.24 \mathrm{kN}$ ) produced $486 \mathrm{mg} / \mathrm{kN}$ and $2891.7 \times 10^{16}$ particles/kN, whereas the CFM56-7B26 (rated thrust $117 \mathrm{kN}$ ) from the previous study 290 of Durdina et al. $(2017)^{31}$ emitted $113 \mathrm{mg} / \mathrm{kN}$ and $2.67 \times 10^{15}$ of particles $/ \mathrm{kN}$. Therefore, the 291 smaller engine investigated here is expected to have worse nvPM emissions performance from 292 LTO operations than the larger engine. 
a)

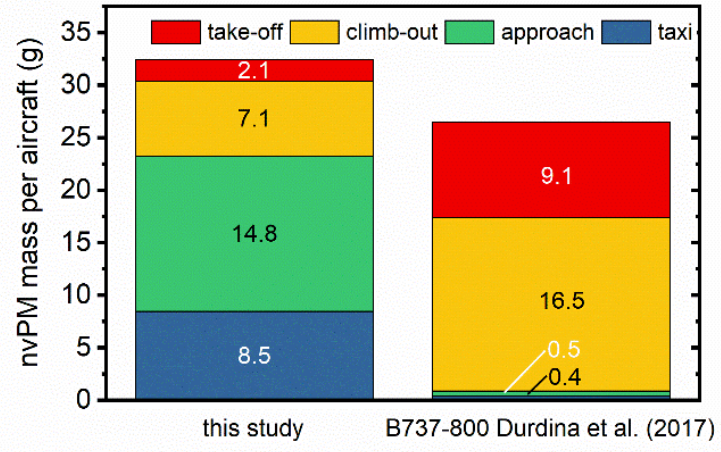

b)

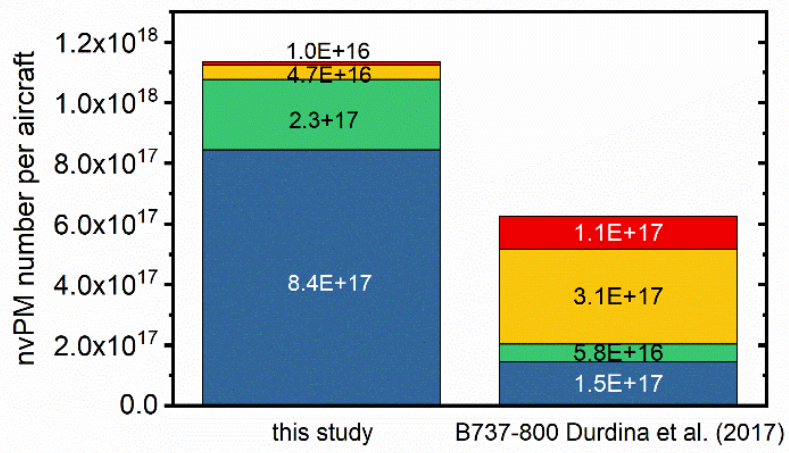

294 Figure 4 LTO cycle emissions of nvPM mass (a) and nvPM number (b) calculated per aircraft.

Table 1 Summary of the LTO emission indices, nvPM mass and number emissions per aircraft and geometric mean diameters ( \pm estimated uncertainties at $95 \%$ confidence).

\begin{tabular}{|c|c|c|c|c|c|c|}
\hline $\begin{array}{l}\text { LTO } \\
\text { mode }\end{array}$ & $\begin{array}{l}\text { LTO time } \\
\text { in mode (s) }\end{array}$ & $\begin{array}{c}E I_{m} \pm u_{95} \\
(\mathrm{mg} / \mathrm{kg})\end{array}$ & $\begin{array}{c}\mathbf{E} \mathbf{I}_{\mathbf{n}} \pm \mathbf{u}_{95} \\
(\# / \mathbf{k g})\end{array}$ & $\begin{array}{l}\text { nvPM mass per } \\
\text { aircraft } \pm u_{95} \\
\text { (g) }\end{array}$ & $\begin{array}{c}\text { nvPM number per } \\
\text { aircraft } \pm \mathbf{u}_{95} \\
\text { (\#) }\end{array}$ & $\begin{array}{c}\text { GMD } \pm \mathbf{u}_{95} \\
(\mathbf{n m})\end{array}$ \\
\hline taxi & 1560 & $57.4 \pm 13.5$ & $5.7 \times 10^{15} \pm 1.5 \times 10^{15}$ & $8.5 \pm 2$ & $8.4 \times 10^{17} \pm 2.2 \times 10^{17}$ & $21.8 \pm 1.4$ \\
\hline approach & 240 & $217.2 \pm 61.5$ & $3.4 \times 10^{15} \pm 9.3 \times 10^{14}$ & $14.8 \pm 4.2$ & $2.3 \times 10^{17} \pm 6.4 \times 10^{16}$ & $36.2 \pm 1.9$ \\
\hline climb-out & 132 & $72 \pm 26$ & $4.7 \times 10^{14} \pm 1.2 \times 10^{14}$ & $7.1 \pm 2.6$ & $4.7 \times 10^{16} \pm 1.2 \times 10^{16}$ & $44.3 \pm 3.4$ \\
\hline take-off & 42 & $59.6 \pm 24.2$ & $2.9 \times 10^{14} \pm 1.8 \times 10^{14}$ & $2.1 \pm 0.9$ & $1.0 \times 10^{16} \pm 6.2 \times 10^{15}$ & $45.5 \pm 3.0$ \\
\hline total & & & & $32.5 \pm 5.4$ & $1.1 \times 10^{18} \pm 2.3 \times 10^{17}$ & \\
\hline
\end{tabular}


299 Cruise emissions. The estimated nvPM EIs at cruising altitudes are shown in Figure 5. For the 300 reference flight level of $35,000 \mathrm{ft}(10.67 \mathrm{~km})$ in $\mathrm{ISA}$, the $\mathrm{EI}_{\mathrm{n}}$ was $7.4 \times 10^{14}$ particles $/ \mathrm{kg}$ of fuel 301 burned, comparable with the previous modeling study for the Boeing $737-800 .{ }^{31}$ In contrast, the $302 \mathrm{EI}_{\mathrm{m}}$ was $82 \mathrm{mg} / \mathrm{kg}$ of fuel burned, which is a factor of $\sim 8$ higher than found for the Boeing 737's 303 engines for the same flight conditions and using the same measurement system and modeling 304 approach. This is due to the larger mean particle size. We estimated the GMD to be $\sim 42 \mathrm{~nm}$ 305 (compared to $22 \mathrm{~nm}$ for the Boeing 737), which means that the particle mass distribution is 306 dominated by a fewer larger particles.

The nvPM EIs decreased with increasing ambient temperature. As ambient temperature increases, the engine runs at higher N1 at the same Mach number to compensate for the lower air density. The T3 increases, which, due to the nvPM emission characteristics of the engine studied 310 (Figure 3), leads to decreasing nvPM EIs. Therefore, flying at higher altitudes and at maximum 311 cruise thrust would result in lower nvPM emissions. This result contrasts the findings of previous 312 studies of commercial turbofan engines with maximum nvPM mass emissions at maximum 313 thrust. ${ }^{31,44}$ Overall, our estimated cruise nvPM mass emissions ( $\left.82 \mathrm{mg} / \mathrm{kg}\right)$, which are most 314 relevant for the direct radiative forcing effects, are higher than literature values used for the fleet 315 average $(25-40 \mathrm{mg} / \mathrm{kg}))^{3,45}$ Despite the small aircraft size and relatively low fuel burn, the nvPM 316 mass emission rates were up to a factor of 3 higher than previously reported for the Boeing 737 317 engines (Figure 5c). 


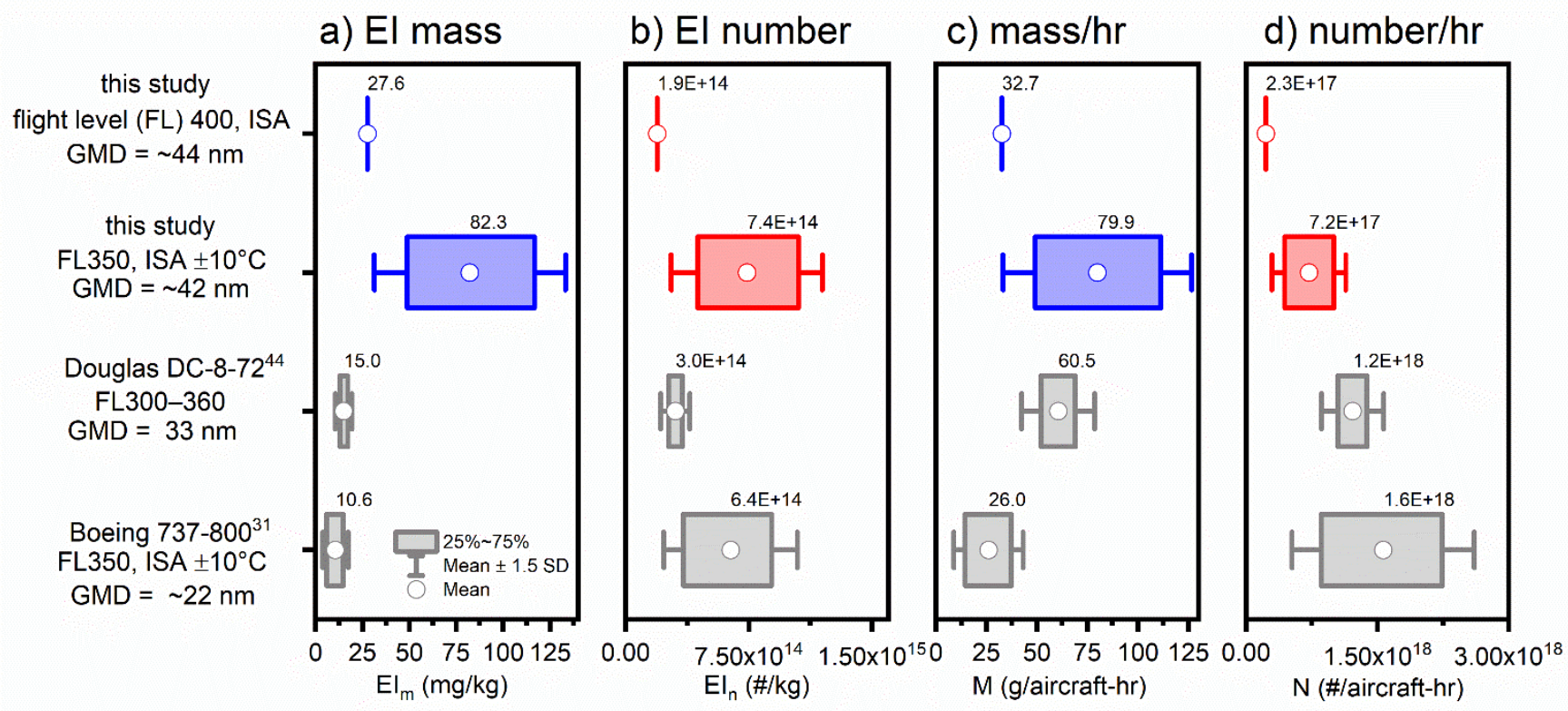

319 Figure 5 Emissions at cruise: EI of nvPM mass (a) EI nvPM number (b) nvPM mass per hour (c) and nvPM number per hour (d). The results for the DC-8-72 were obtained from exhaust plume sampling at cruise behind the aircraft flying at maximum range thrust burning medium- and low sulfur Jet A-1 fuel. ${ }^{44}$ The results for the Boeing 737-800 were modeled using an engine performance model and ground test data of the CFM56-7B engine. ${ }^{31}$ inventories and have also been excluded from the certification requirements for nvPM emissions as well as for gaseous emissions. We have shown here that a modern business jet may emit as much nvPM from airport operations as an airliner. Also, the comparison with airliners at the

330 cruising altitude suggests that nvPM emissions from a business jet flight may be higher than 331 those of an airliner. 
The thrust dependence of nvPM mass emissions of the engine investigated differed from those of large turbofan engines, on which predictive models are based. Models that predict aviation nvPM mass emissions at ground level and cruising altitude ${ }^{16,17}$ are calibrated to measurement data of engines that produce maximum nvPM mass emissions at take-off thrust. The models predict lowest nvPM mass emissions at idle and an exponential increase with increasing thrust. Thus, the nvPM emissions of the engine type investigated here cannot be well predicted using such a modeling approach without engine-specific SN or nvPM data.

Our nvPM measurements and modeled cruise emissions allowed comparison with previous studies of large engines at ground and at cruise. The ground level emission measurements have shown that the high thrust modes produced the lowest nvPM emissions, however, the low power conditions, which dominated the LTO cycle, produced up to an order of magnitude more nvPM mass and number than a Boeing 737 airliner. Consequently, taxiing aircraft with nvPM emission characteristics as found here may be an important pollution source at ground. Relatively high nvPM EIs were found also at cruise condition. If we expand the comparison with the Boeing 737 nvPM emissions ${ }^{31}$ to the overall flight emissions, during a 2hour cruise and the regulatory LTO cycle, the business jet would produce $190 \mathrm{~g}$ of nvPM and $2.54 \times 10^{18}$ of particles, which is twice as much nvPM mass and $\sim 65 \%$ of the nvPM number of the airliner. Expressed as a per-person burden (assuming 180 airliner passengers and 5 business jet passengers), the nvPM mass emissions are higher by a factor of 72 and the nvPM number emissions are higher by a factor of 24 .

These results highlight the need for further emissions research of small aircraft engines. To evaluate the applicability of our results, future studies should investigate nvPM mass and number emissions and size distributions as a function of engine thrust of different engine types to 
355 develop emission inventories and more robust predictive models for ground and cruise

356 emissions. This study will serve for the development of emission inventories and the results

357 could also be used in the regulatory framework for assessing the emissions certification

358 requirements of small aircraft turbine engines.

\section{ASSOCIATED CONTENT}

361 Supporting Information. Fuel properties, engine test matrix, system loss correction factors, 362 engine performance model and cruise emission calculation.

364 AUTHOR INFORMATION

365 Corresponding Author

366 *Phone: +41 5893475 24. Fax: +41 5893575 24. E-mail: lukas.durdina@,zhaw.ch

$367 \quad$ Notes

368 The authors declare no competing financial interest.

\section{ACKNOWLEDGEMENTS}

370 Funding was provided by the Swiss Federal Office of Civil Aviation (FOCA). We thank the

371 Swiss Air Force for providing the aircraft and facilities, namely Ralph Loosli, Thierry Dey,

372 Michael Lüthy (crew Bern), Thierry Roulin, Canisius Brodard, Bruno Carrard, Pierre Dubi,

373 Christian Guillaume, Christian Bangerter (crew Payerne). We thank Rudy Dudebout from

374 Honeywell Aerospace for providing engine performance data. We thank MeteoSwiss for the 375 meteorological data. Thanks to Dr. Jacinta Edebeli for proofreading the article. 
(1) Fleming, G. G.; Ziegler, U. Environmental Trends in Aviation to 2050. ICAO Environmental Report 2016, p $16-22$.

(2) Climate Change 2007: Synthesis Report; Contribution of Working Groups I, II and III to the Fourth Assessment Report of the Intergovernmental Panel on Climate Change; IPCC: Geneva, Switzerland, 2007.

(3) Lee, D. S.; Fahey, D. W.; Forster, P. M.; Newton, P. J.; Wit, R. C.N.; Lim, L. L.; Owen, B.; Sausen, R. Aviation and global climate change in the 21st century. Atmos. Environ. 2009, 43, 3520-3537; DOI

382

383

384 10.1016/j.atmosenv.2009.04.024.

(4) Lee, D. S.; Pitari, G.; Grewe, V.; Gierens, K.; Penner, J. E.; Petzold, A.; Prather, M. J.; Schumann, U.; Bais, A.; Berntsen, T.; Iachetti, D.; Lim, L. L.; Sausen, R. Transport impacts on atmosphere and climate: Aviation. Atmos. Environ. 2010, 44, 4678-4734; DOI: 10.1016/j.atmosenv.2009.06.005.

(5) Environmental Protection, Volume II - Aircraft Engine Emissions, Fourth edition; Annex 16 to the Convention on International Civil Aviation; ICAO: Montréal, Quebec, Canada, 2017.

(6) Rindlisbacher, T.; Jacob, S. D. New particulate matter standard for aircraft gas turbine engines. ICAO Environmental Report 2016, p 85-88.

(7) Winther, M.; Kousgaard, U.; Ellermann, T.; Massling, A.; Nøjgaard, J. K.; Ketzel, M. Emissions of NOx, particle mass and particle numbers from aircraft main engines, APU's and handling equipment at Copenhagen Airport. Atmos. Environ. 2015, 100, 218-229; DOI: 10.1016/j.atmosenv.2014.10.045.

(8) Riley, E. A.; Gould, T.; Hartin, K.; Fruin, S. A.; Simpson, C. D.; Yost, M. G.; Larson, T. Ultrafine particle size as a tracer for aircraft turbine emissions. Atmos. Environ. 2016, 139, 20-29; DOI: /10.1016/j.atmosenv.2016.05.016.

(9) Lobo, P.; Hagen, D. E.; Whitefield, P. D. Measurement and analysis of aircraft engine PM emissions downwind of an active runway at the Oakland International Airport. Atmos. Environ. 2012, 61, 114-123; DOI:

10.1016/j.atmosenv.2012.07.028.

(10) Hudda, N.; Gould, T.; Hartin, K.; Larson, T. V.; Fruin, S. A. Emissions from an international airport increase particle number concentrations 4-fold at $10 \mathrm{~km}$ downwind. Environ. Sci. Technol. 2014, 48, 6628-6635; DOI: $10.1021 /$ es5001566.

(11) Keuken, M. P.; Moerman, M.; Zandveld, P.; Henzing, J. S.; Hoek, G. Total and size-resolved particle number and black carbon concentrations in urban areas near Schiphol airport (the Netherlands). Atmos. Environ. 2015, 104, 132-142; DOI: 10.1016/j.atmosenv.2015.01.015.

(12) Kinsey, J. S.; Dong, Y.; Williams, D. C.; Logan, R. Physical characterization of the fine particle emissions from commercial aircraft engines during the Aircraft Particle Emissions eXperiment (APEX) 1-3. Atmos. Environ. 2010, 44, 2147-2156; DOI: 10.1016/j.atmosenv.2010.02.010.

(13) Petzold, A.; Fiebig, M.; Fritzsche, L.; Stein, C.; Schumann, U.; Wilson, C. W.; Hurley, C. D.; Arnold, F.; Katragkou, E.; Baltensperger, U.; Gysel, M.; Nyeki, S.; Hitzenberger, R.; Giebl, H.; Hughes, K. Particle emissions from aircraft engines a survey of the European project PartEmis. Meteorol Z. 2005, 14, 465-476; DOI:

$10.1127 / 0941-2948 / 2005 / 0054$.

(14) Timko, M. T.; Onasch, T. B.; Northway, M. J.; Jayne, J. T.; Canagaratna, M. R.; Herndon, S. C.; Wood, E. C.; Miake-Lye, R. C.; Knighton, W. B. Gas Turbine Engine Emissions-Part II: Chemical Properties of Particulate Matter. J. Eng. Gas Turbines Power 2010, 132, 61505; DOI: 10.1115/1.4000132.

(15) Petzold, A.; Marsh, R.; Johnson, M.; Miller, M.; Sevcenco, Y.; Delhaye, D.; Ibrahim, A.; Williams, P.; Bauer, H.; Crayford, A.; Bachalo, W. D.; Raper, D. Evaluation of methods for measuring particulate matter emissions from gas turbines. Environ. Sci. Technol. 2011, 45, 3562-3568 ; DOI: 10.1021/es103969v.

(16) Stettler, M. E. J.; Boies, A. M.; Petzold, A.; Barrett, S. R. H. Global civil aviation black carbon emissions. Environ. Sci. Technol. 2013, 47, 18; DOI: 10.1021/es401356v.

(17) Abrahamson, J. P.; Zelina, J.; Andac, M. G.; Vander Wal, R. L. Predictive model development for aviation black carbon mass emissions from alternative and conventional fuels at ground and cruise. Environ. Sci. Technol. 2016, 50, 21; DOI: 10.1021/acs.est.6b03749.

(18) Lobo, P.; Durdina, L.; Smallwood, G. J.; Rindlisbacher, T.; Siegerist, F.; Black, E. A.; Yu, Z.; Mensah, A. A.; Hagen, D. E.; Miake-Lye, R. C.; Thomson, K. A.; Brem, B. T.; Corbin, J. C.; Abegglen, M.; Sierau, B.; Whitefield, P. D.; Wang, J. Measurement of Aircraft Engine Non-Volatile PM Emissions: Results of the Aviation-Particle Regulatory Instrumentation Demonstration Experiment (A-PRIDE) 4 Campaign. Aerosol Sci. Technol. 2015, 49, 472-484; DOI: 10.1080/02786826.2015.1047012.

(19) Lobo, P.; Condevaux, J.; Yu, Z.; Kuhlmann, J.; Hagen, D. E.; Miake-Lye, R. C.; Whitefield, P. D.; Raper, D. W. Demonstration of a Regulatory Method for Aircraft Engine Nonvolatile PM Emissions Measurements with 
Conventional and Isoparaffinic Kerosene fuels. Energ. Fuel. 2016, 30, 7770-7777; DOI: 10.1021/acs.energyfuels.6b01581.

(20) Brem, B. T.; Durdina, L.; Siegerist, F.; Beyerle, P.; Bruderer, K.; Rindlisbacher, T.; Rocci-Denis, S.; Andac, M. G.; Zelina, J.; Penanhoat, O.; Wang, J. Effects of Fuel Aromatic Content on Nonvolatile Particulate Emissions of an In-Production Aircraft Gas Turbine. Environ. Sci. Technol. 2015, 49, 13149-13157; DOI: 10.1021/acs.est.5b04167.

(21) Durdina, L.; Lobo, P.; Trueblood, M. B.; Black, E. A.; Achterberg, S.; Hagen, D. E.; Brem, B. T.; Wang, J. Response of real-time black carbon mass instruments to mini-CAST soot. Aerosol Sci. Technol. 2016, 50, 906-918; DOI: $10.1080 / 02786826.2016 .1204423$.

(22) Durdina, L.; Brem, B. T.; Abegglen, M.; Lobo, P.; Rindlisbacher, T.; Thomson, K. A.; Smallwood, G. J.; Hagen, D. E.; Sierau, B.; Wang, J. Determination of PM mass emissions from an aircraft turbine engine using particle effective density. Atmos. Environ. 2014, 99, 500-507; DOI: 10.1016/j.atmosenv.2014.10.018.

(23) 10-Year Market Forecast; Jetcraft: Raleigh, NC, 2017. https://jetcraft.com/outlook/Jetcraft-10-Year-MarketForecast-2017.pdf (accessed Sept 19, 2019).

(24) NBAA Business Aviation Factbook; National Business Aviation Association: Washington, DC, United States, 2018. https://nbaa.org/wp-content/uploads/2018/01/business-aviation-fact-book.pdf (accessed Sept 19, 2019).

(25). Business Aviation Commitment on Climate Change: An Update; International Business Aviation Council: Montreal, Canada, 2016. http://www.ibac.org/wp-content/uploads/2016/07/GAMA-

IBAC_Environment_Brochure.pdf (accessed Sept 19, 2019).

(26) ICAO Aircraft Engine Emissions Databank. http://easa.europa.eu/node/15672 (accessed Sept 19, 2019).

(27) Wayson, R. L.; Fleming, G. G.; Iovinelli, R. Methodology to Estimate Particulate Matter Emissions from Certified Commercial Aircraft Engines. J. Air Waste Manage. 2009, 59, 91-100; DOI: 10.3155/1047-3289.59.1.91. (28) Agarwal, A.; Speth, R. L.; Fritz, T. M.; Jacob, S. D.; Rindlisbacher, T.; Iovinelli, R. Owen, B.; Miake-Lye, R. C.; Sabnis, J. S.; Barrett, S. R. H. (2019). SCOPE11 Method for Estimating Aircraft Black Carbon Mass and Particle Number Emissions. Environ. Sci. Technol. 2019, 53 (3), 1364-1373; DOI: 10.1021/acs.est.8b04060.

(29) Yu, Z., Liscinsky, D. S., Fortner, E. C., Yacovitch, T. I., Croteau, P., Herndon, S. C., Miake-Lye, R. C. Evaluation of PM emissions from two in-service gas turbine general aviation aircraft engines. Atmos. Environ. 2017, 160, 9-18; DOI:10.1016/j.atmosenv.2017.04.007.

(30) JET A1 vs JP-8 Differences and Effects on Long Term Use. https://quartermaster.army.mil/pwd/Papers/JETA1 Vs JP8.pdf (accessed 19 Sept, 2019).

(31) Durdina, L.; Brem, B. T.; Setyan, A.; Siegerist, F.; Rindlisbacher, T.; Wang, J. Assessment of Particle Pollution from Jetliners: From Smoke Visibility to Nanoparticle Counting. Environ. Sci. Technol. 2017, 51, 35343541; DOI: 10.1021/acs.est.6b05801.

(32) Procedure for the Calculation of Non-Volatile Particulate Matter Sampling and Measurement System Losses and System Loss Correction Factors; Aerospace Recommended Practice ARP6481; SAE International: Warrendale, PA, 2019.

(33) Procedure for the Continuous Sampling and Measurement of Non-Volatile Particulate Matter Emissions from Aircraft Turbine Engines; Aerospace Recommended Practice ARP6320; SAE International: Warrendale, PA, 2016.

(34) Kurzke, J. A physics-based methodology for building accurate gas turbine performance models. ISABE 2015: 22nd ISABE Conference, 2015.

(35) Döpelheuer, A.; Lecht, M. Influence of engine performance on emission characteristics. RTO Meeting Proceedings 14; RTO/NATO: Hull, Canada, 1999.

(36) Experimental Characterization of Gas Turbine Emissions at Simulated Altitude Conditions; AEDC-TR-96-3; Arnold Engineering Development Center, Tullahoma, TN, 1996. https://ntrs.nasa.gov/archive/nasa/casi.ntrs.nasa.gov/19970016783.pdf (accessed 19 Sept, 2019).

(37) Beyersdorf, A. J.; Timko, M. T.; Ziemba, L. D.; Bulzan, D.; Corporan, E.; Herndon, S. C.; Howard, R.; MiakeLye, R.; Thornhill, K. L.; Winstead, E.; Wey, C.; Zu, Y.; Anderson, B. E. Reductions in aircraft particulate emissions due to the use of Fischer-Tropsch fuels. Atmos. Chem. Phys. 2014, 14, 11-23; DOI: 10.5194/acp-14-112014.

(38) Delhaye, D.; Ouf, F.-X.; Ferry, D.; Ortega, I. K.; Penanhoat, O.; Peillon, S.; Salm, F.; Vancassel, X.; Focsa, C.; Irimiea, C.; Harivel, N.; Perez, B.; Quinton, E.; Yon, J.; Gaffie, D. The MERMOSE project: Characterization of particulate matter emissions of a commercial aircraft engine. J. Aerosol Sci. 2017, 105, 48-63; DOI: doi.org/10.1016/j.jaerosci.2016.11.018.

(39) Lobo, P.; Hagen, D. E.; Whitefield, P. D.; Alofs, D. J. Physical Characterization or Aerosol Emissions from a Commercial Gas Turbine Engine. J. Propul. Power 2007, 23, 919-929; DOI: 10.2514/1.26772. 
485

486

487

488

489

490

491

492

493

494

495

496

497

498

499

500

501

502

503

504

505

506

507

508

509
(40) Peck, J.; Oluwole, O. O.; Wong, H.-W.; Miake-Lye, R. C. An algorithm to estimate aircraft cruise black carbon emissions for use in developing a cruise emissions inventory. J. Air Waste Manage. 2013, 63, 367-375; DOI: 10.1080/10962247.2012.751467.

(41) Christie, S.; Lobo, P.; Lee, D.; Raper, D. Gas Turbine Engine Nonvolatile Particulate Matter Mass Emissions: Correlation with Smoke Number for Conventional and Alternative Fuel Blends. Environ. Sci. Technol. 2017, 51, 988-996; DOI: 10.1021/acs.est.6b03766.

(42) Schripp, T.; Anderson, B.; Crosbie, E. C.; Moore, R. H.; Herrmann, F.; Oßwald, P.; Wahl, C.; Kapernaum, M.; Köhler, M.; Le Clercq, P.; Rauch, B.; Eichler, P.; Mikoviny, T.; Wisthaler, A. Impact of Alternative Jet Fuels on Engine Exhaust Composition During the 2015 ECLIF Ground-Based Measurements Campaign. Environ. Sci. Tchnol. 2018, 52, 4969-4978; DOI: 10.1021/acs.est.7b06244.

(43) World fuel sampling program; CRC Report No. 647; Coordinating Research Council: Alpharetta, GA, 2006. (44) Moore, R. H.; Thornhill, K. L.; Weinzierl, B.; Sauer, D.; D’Ascoli, E.; Kim, J.; Lichtenstern, M.; Scheibe, M.; Beaton, B.; Beyersdorf, A. J.; Barrick, J.; Bulzan, D.; Corr, C.A.; Crosbie, E.; Jurkat, T.; Martin, R.; Riddick, D.; Shook, M.; Slover, G.; Voigt, C.; White, R.; Winstead, W.; Yasky, R.; Ziemba, L. D.; Brown, A.; Schlager, H.; Anderson, B. E. Biofuel blending reduces particle emissions from aircraft engines at cruise conditions. Nature 2017, 543, 411-415; DOI: 10.1038/nature21420.

(45) Aviation and the global atmosphere; A special report of IPCC Working Groups I and III in collaboration with the Scientific Assessment Panel to the Montreal Protocol on Substances that Deplete the Ozone Layer; IPCC:

Geneva, Switzerland, 1999. 


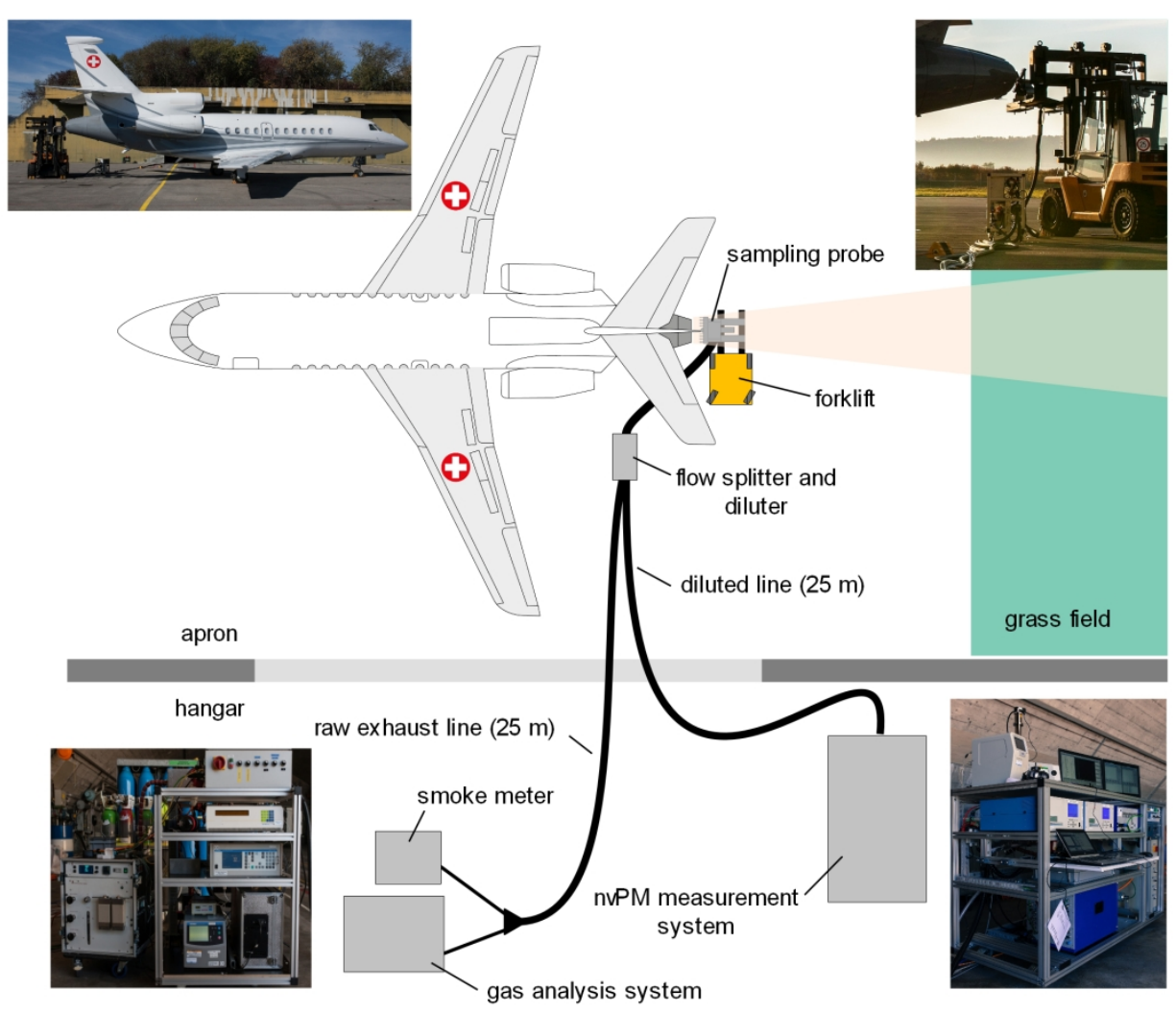

Figure 1

$184 \times 160 \mathrm{~mm}(300 \times 300$ DPI) 


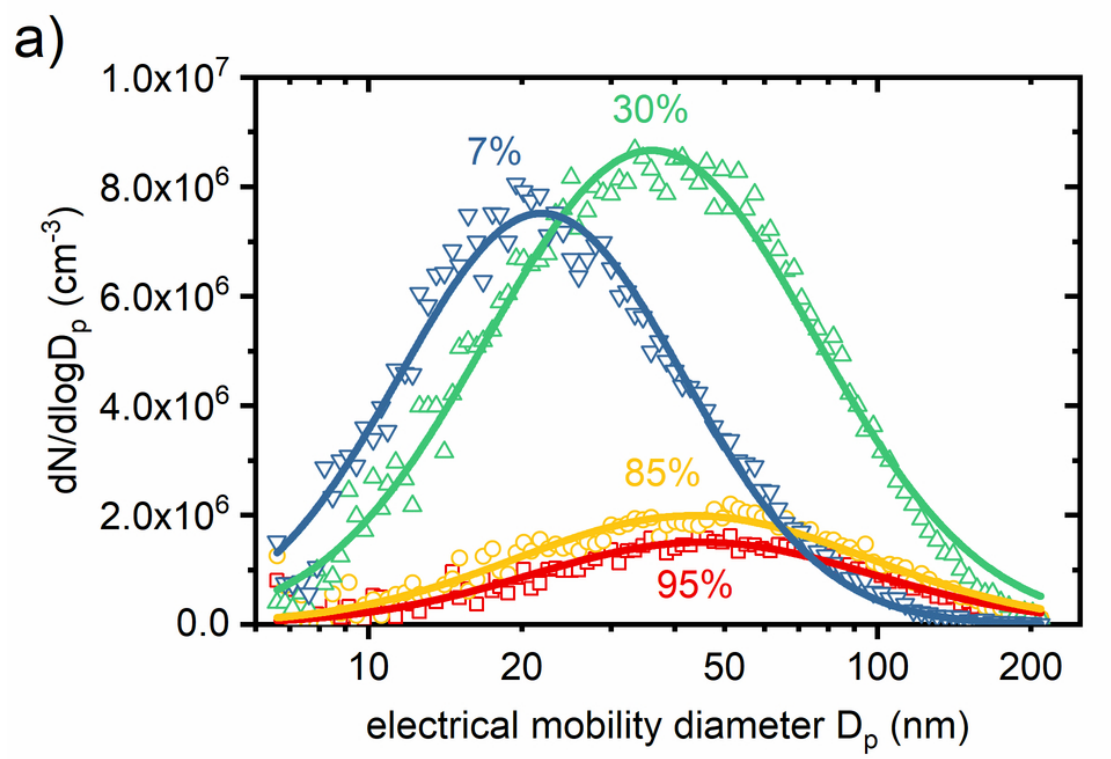

b)

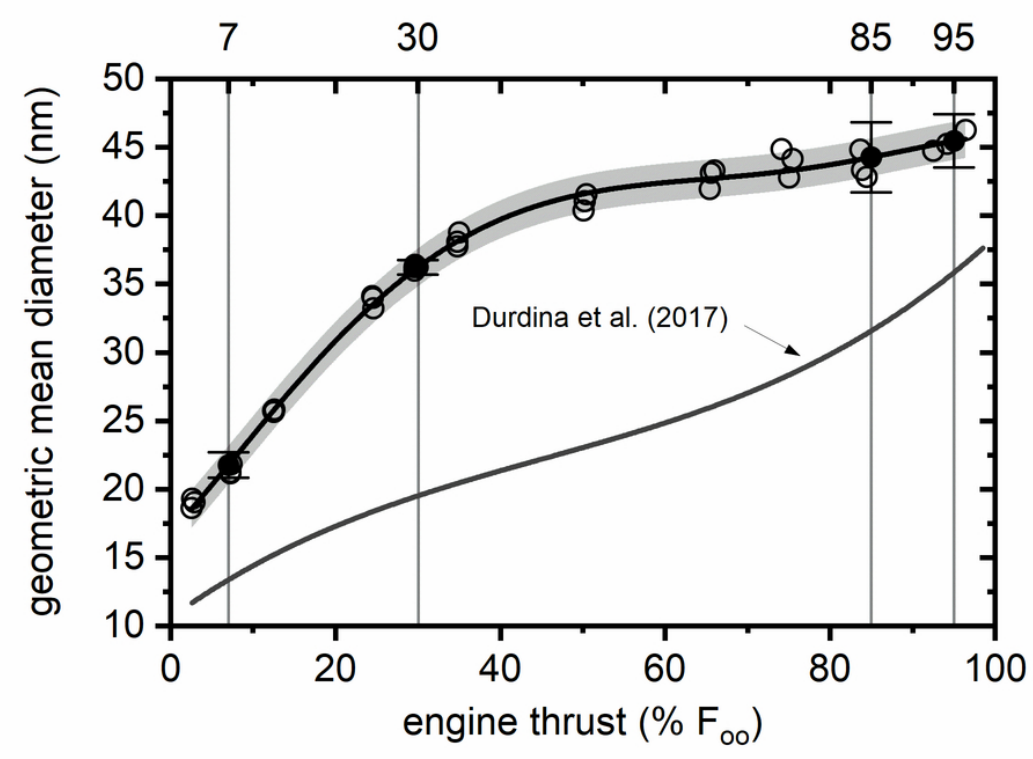

Figure 2

$82 \times 114 \mathrm{~mm}(300 \times 300 \mathrm{DPI})$ 

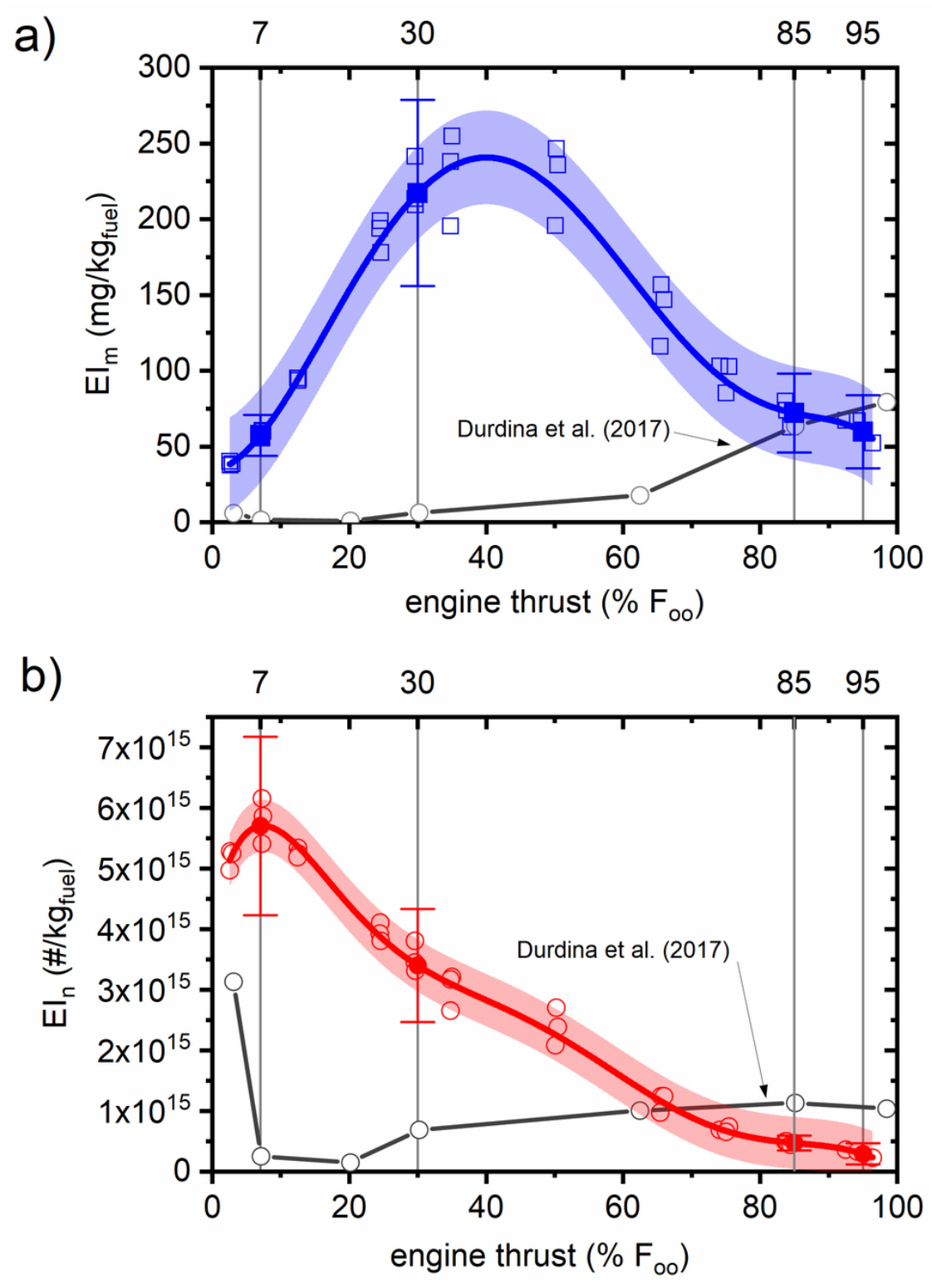

Figure 3

$82 \times 114 \mathrm{~mm}(300 \times 300 \mathrm{DPI})$ 
a)

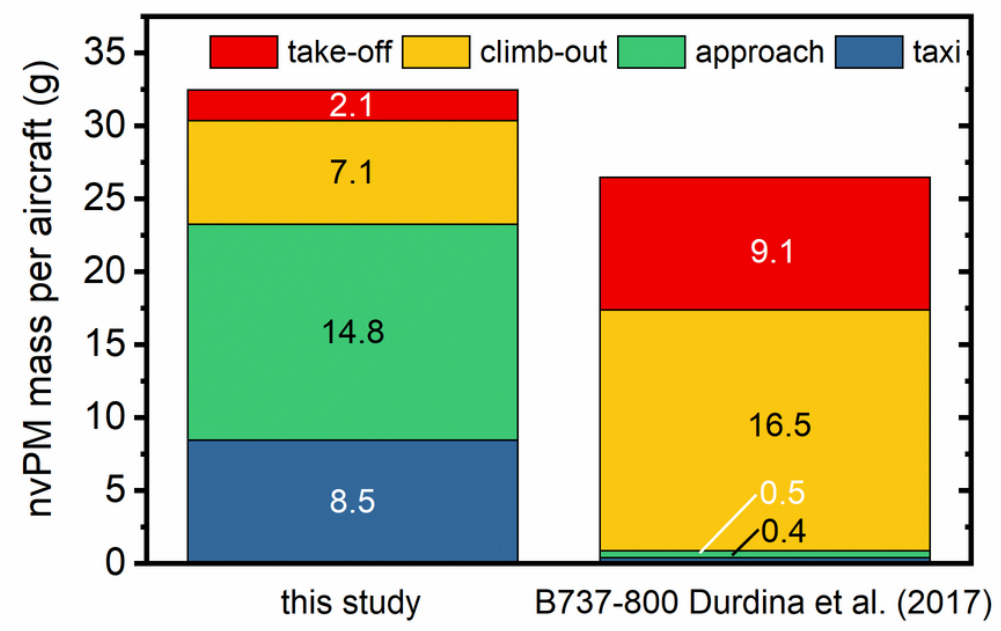

b)

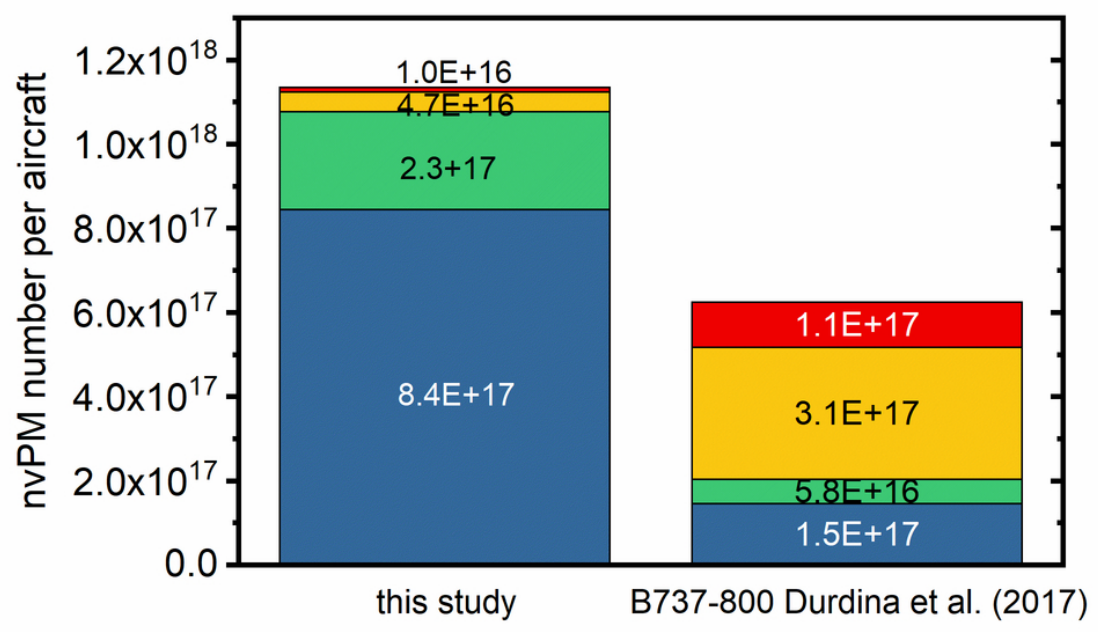

Figure 4

$82 \times 114 \mathrm{~mm}(300 \times 300$ DPI $)$ 


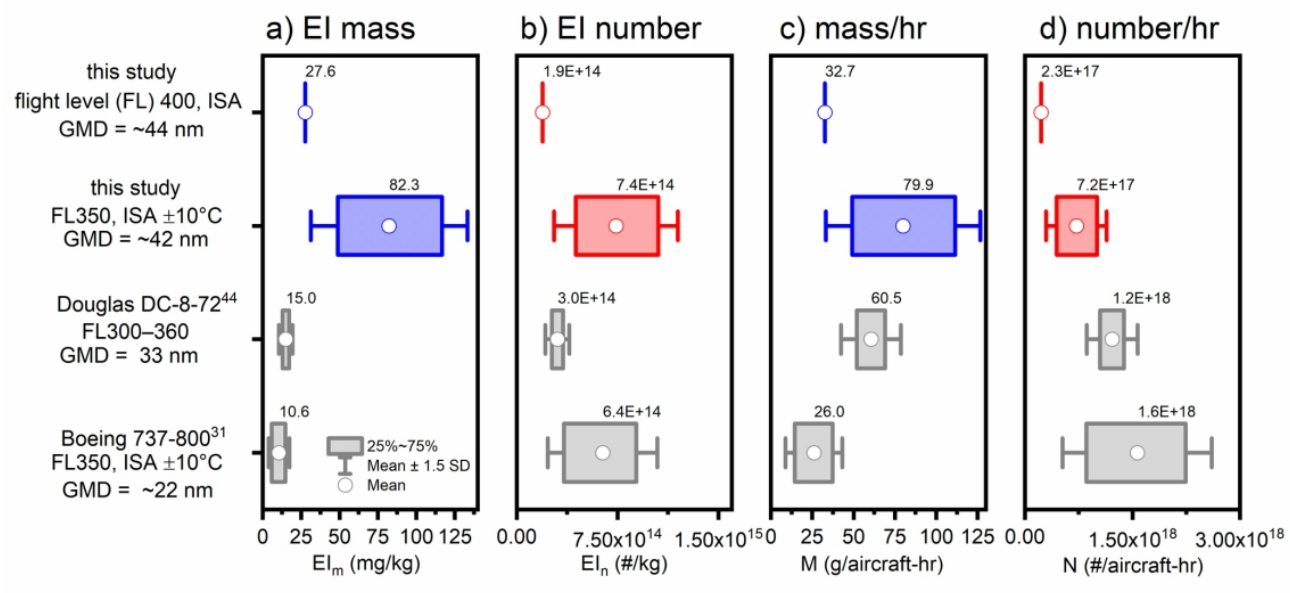

Figure 5

$177 \times 82 \mathrm{~mm}(300 \times 300 \mathrm{DPI})$ 


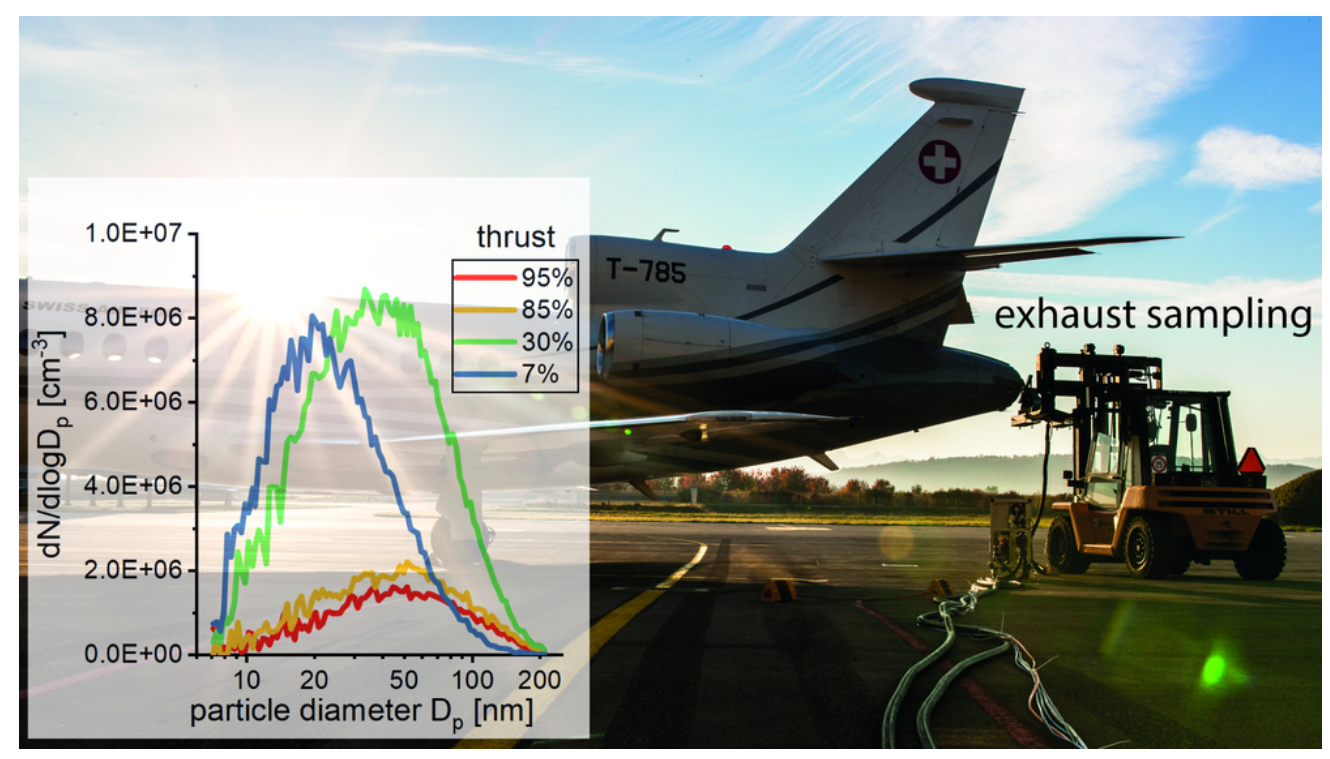

graphical abstract

$84 \times 47 \mathrm{~mm}(300 \times 300$ DPI $)$ 